\title{
Serine/Threonine-Protein Kinase PLK1
}

National Cancer Institute

\section{Source}

National Cancer Institute. Serine/Threonine-Protein Kinase PLK1. NCI Thesaurus. Code C17911.

Serine/threonine-protein kinase PLK1 (603 aa, $68 \mathrm{kDa}$ ) is encoded by the human PLK1 gene. This protein is involved in protein phosphorylation and the regulation of both cell cycle progression and cytokinesis. 